\title{
Galapagos tortoise disease 'contained'
}

Paris. Researchers and conservationists said last week that they have contained the outbreak of a mystery disease that has killed eight giant tortoises and affected nine others on the Galapagos island of Santa Cruz.

But the cause of the deaths has yet to be established. And the outbreak has reopened a stormy debate over the potential threat to the Galapagos ecosystem from human activity, including agriculture.

About 20,000 giant tortoises live in the Galapagos archipelago. The deaths, which were first reported last month, have all occurred in and around a large pond in $\mathrm{El}$ Chato, a region within the Galapagos National Park that is open to visitors.

The pond is one of the few waterholes in the area to have survived recent droughts, and has attracted many tortoises, as well as cattle, goats, pigs, dogs and other animals from a nearby farming region.

The tortoises' symptoms include general

fatigue, secretions from the eyes, nose and mouth, and difficulty in breathing, with the exhaled air having a putrid odour. A similar outbreak in the same area in 1979 killed five tortoises, but it was detected too late for samples to be taken from the already decomposed animals.

"When animals die in the field you have to be very lucky to get one fresh," says Elliott Jacobson, a professor of zoological medicine at the University of Florida, who heads the team studying the pathology of the new outbreak. "Many changes that Tortoises at risk: human activities may be a factor. occur in tissues shortly after death mask everything."

This time, blood and faecal samples were taken from several animals immediately after they died by staff at the Galapagos National Park Service and the Charles Darwin Research Station. The research

\section{Appeal to reprieve Canadian cyclotron}

Ottawa. More than 700 scientists from 37 countries have appealed to Canada's prime minister to save the Tandem Accelerator Superconducting Cyclotron Facility (TASCC) at Chalk River Laboratories, the country's only heavy-ion research centre.

The appeal has been made in the form of a paid advertisement in the Toronto newspaper The Globe and Mail. Signatories include six Nobel prizewinners, the presidents of six national physical societies and the directors of ten major world laboratories.

TASCC is under threat following a decision by the federal government last March to cut nearly C $\$ 75$ million (US $\$ 55$ million) from the $C \$ 175$ million budget of Atomic Energy of Canada Ltd (AECL) (see Nature 380, 92; 1996). Both the cyclotron facility and the condensedmatter science programme were given until next March to find alternative funds.

D. Allan Bromley, the former US presidential science adviser, describes TASCC in the advertisement as "the best such anywhere in the world today and I think I have seen them all". Sir Denys Wilkinson, former vice-chancellor of the University of Sussex in the United Kingdom, is quoted as saying in a letter to Anne McLellan, the minister of natural resources, that there are "very few areas in respect of which Canada occupies an uncontested place at the top table; nuclear structure physics through TASCC is one of these".

Despite receiving more than 200 letters of support for TASCC, McLellan has said for the past six months that she is too busy to meet representatives of the cyclotron facility, according to John Hardy, its director. Other senior government ministers say they cannot help without McLellan's approval.

"The [open] letter [tactic] was chosen because we don't think we have the government's attention," says Hardy. The National Research Council of Canada is known to be interested in taking over the project, but does not have funds available.

The Aerospace Industries Association of Canada has indicated its interest in discussing a possible future partnership. TASCC already does nearly $\mathrm{C} \$ 1$ million worth of business annually with aerospace industries.

The most telling pressure for TASCC funding may come from the town of Deep River, near which AECL is located. This small community is the only one in Canada that has agreed to the nearby burial of low-level nuclear waste from Canada's reactors - something the federal government is anxious to see.

But the town's agreement contains a condition: that the number of AECL jobs will not fall from its level in March last year. It is already 200 jobs below that, and the disbanding of TASCC and the condensed-matter science programme would increase the job losses by a further 100. These would include scientists with expertise in nuclear-waste disposal. The government could lose the town's approval for nuclear-waste disposal if the jobs are lost.

David Spurgeon

\section{IMAGE \\ UNAVAILABLE \\ FOR COPYRIGHT REASONS}

station is part of the Charles Darwin Foundation, an international nonprofit organization set up in 1959 to carry out research in the Galapagos Islands.

Such an operation in this remote area would also have been impossible before the advent of electronic mail, says Jacobson. "Tissue collection and handling is very complicated," he says, and it is impractical "to have a team standing around" because outbreaks occur rarely.

E-mail allowed Jacobson and other scientists to coordinate with staff in the Galapagos to develop protocols with the limited materials and reagents they had in hand or were able to obtain from the Gustavo Orces Herpetological Foundation in Quito on the mainland of Ecuador.

Nevertheless, what killed the tortoises may be established, if at all, only after a long and tortuous investigation. Establishing the cause of death in wild mammals is difficult enough, but it relatively straightforward compared with the problem in reptiles, where the field is in its infancy. Jacobson, an expert on tortoise diseases, points out that diseases in desert and gopher tortoises are probably the best understood among those of reptiles, but that even in these cases "we still don't understand the dynamics".

As for the Galapagos outbreak, pathological studies may point the investigation in the right direction, but for now it is not even known whether the disease is infectious.

The working hypothesis is that it may have resulted from a combination of factors. The tortoises have taken to eating introduced passion fruit, for example, which may have reduced the nutritional value of their diet and made them susceptible to usually innocuous threats, such as nematode infections, algal blooms or pesticides.

Although agriculture has not yet been identified as the culprit that caused the outbreak, suspicion that this is the case has reopened the debate over the risks posed to the Galapagos ecosystem by human activities, in particular because the pond where the outbreak occurred is shared by farm animals.

Declan Butler 